\title{
MALE-FEMALE COMMUNICATION IN THE CRAYFISH ORCONECTES RUSTICUS: THE USE OF URINARY SIGNALS IN REPRODUCTIVE AND NON-REPRODUCTIVE PAIRINGS
}

\author{
Jodie L. Simon
}

\begin{abstract}
A Thesis
Submitted to the Graduate College of Bowling Green

State University in partial fulfillment of the requirements for the degree of
\end{abstract}

\section{MASTER OF SCIENCE}

August 2006

Committee:

Paul A. Moore, Advisor

Sheryl L. Coombs

Rex L. Lowe 


\begin{abstract}
Paul A. Moore, Advisor

Animals use sensory communication to locate conspecifics, food, shelter, and avoid predators. Using urine visualization techniques as well as Digital Particle Illumination Velocimetry, we examined the role of urinary signals and current generations during social interactions of male and female crayfish. Both reproductive and non-reproductive crayfish were paired to gain a better understanding of how reproductive state influences communication. Analyses of agonistic and mating events were paired in time with recorded urine release and current generation, illustrating a correlation of chemical communication with ritualistic social behavior. Four treatment groups were run with various pairings of reproductively: (1) both opponents reproductively active, (2) only the male in reproductive, (3) only the female reproductive, or (4) both opponents non-reproductive. Results showed differences between treatment groups in urine release, current generation, and social behavior. Within reproductive pairings, both the male and female crayfish generated currents and released urine at higher rates then those in other treatment groups. Urine was released most often when opponents were in chelae contact with each other and these releases were often accompanied by anterior current generation. There were few differences in between males and females in utilization of chemical and mechanical signals. Overall, there was recognition of reproductive state and subsequent changes in behavior in both the male and female crayfish. This study provides additional evidence that both males and females are affected by their own reproductive state and the reproductive state of conspecifics.
\end{abstract}




\section{DEDICATION}

To the crayfish! To the hours spent collecting them amongst mayflies, t.p.t., and odd and toxic things dumped in the river. To water in my waiters when I gracefully or not-so-gracefully fell.

To hours spent drilling holes through stainless steel, and even more hours spent vacuuming water. To the Black Phoenix and mediocre cafeteria food. To Hilltop and Siberia. To tin shacks and a beautiful lake.

To those who pushed me from behind, and those who pulled me from the front.

Thank you 


\section{ACKNOWLEDGEMENTS}

My most important and profound acknowledgment goes to Dr. Paul A. Moore. I would like to thank him for hours of scientific and life chatter. Thank you for guiding me in my development as a scientist. Thank you for allowing me the opportunity to join your lab and to learn from the tallest man, and mostly for balancing my roller coaster. To my committee, Drs. Sheryl Coombs and Rex Lowe, thank you for your help in the project design and manuscript completion of my thesis.

My biggest thanks to all the members of the Laboratory for Sensory Ecology. Kandi Fero, Mary Wolf, Rachelle Belanger, Christine Johnston, and Jennn Bergner, thank you for hours of assistance in experimental design, data collection, and manuscript editing. I especially want to thank LSE member Art Martin. Thank you for the hours of assistance and numerous runs to D.Q. without out which this thesis would not have been completed. You have kept me sane

I am appreciative of Bowling Green State University for allowing me to complete my master's degree within its walls, and giving me a small paycheck along the way. I would also like to thank the University of Michigan Biological Station for supporting me through financial aid for housing and research, and allowing me space to do complete this thesis. Support for this research was also supplied by NSF (IBN-0131320).

My fondest appreciation goes out to my family and friends who have supported me through this whole process. To my parents, you are the reason I have achieved so much. To Jennifer Schmitz, I could not ask for a better friend. Whether I needed an editor, a supporter, or a shove, you were there. Thank you. And finally my utter appreciation goes to Chad Lasco. Your love and support has been my greatest motivation through this all. You have kept me grounded and let me dream. Thank you. 
TABLE OF CONTENTS

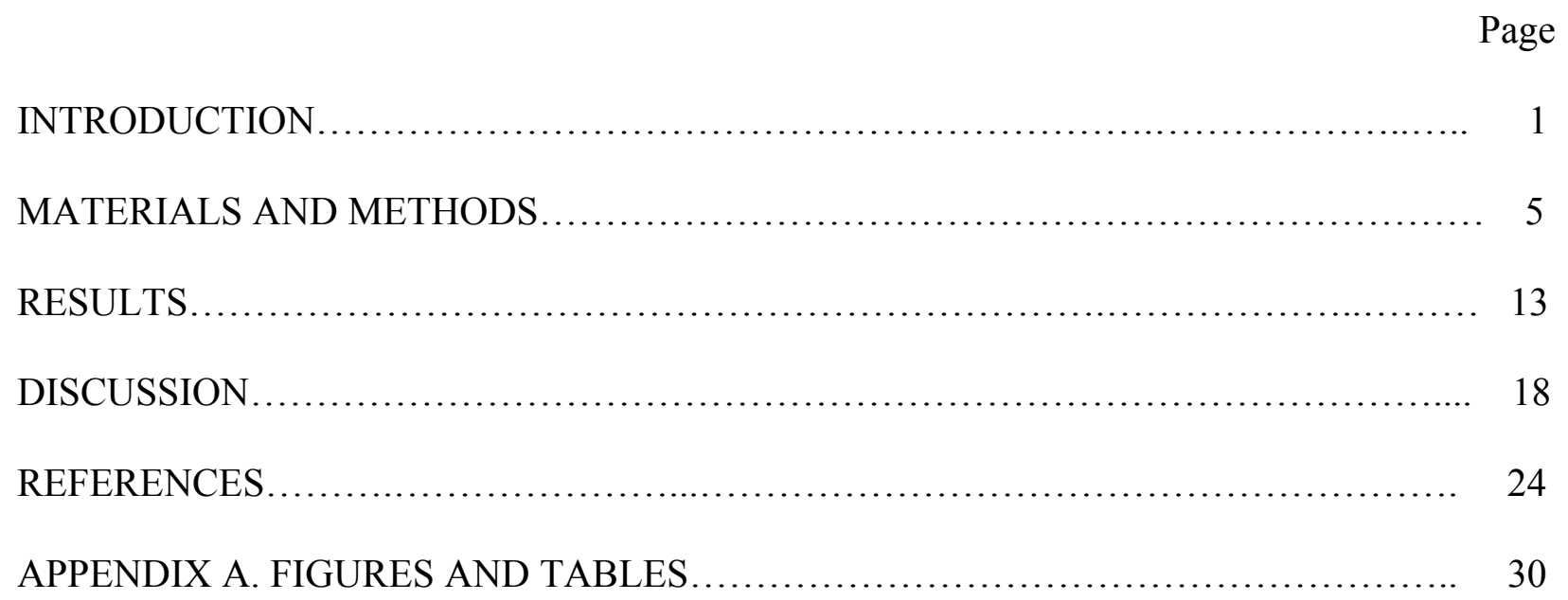




\section{LIST OF FIGURES AND TABLES}

Figure $\quad$ Page

1 Identification of male reproductive state by morphology $\ldots \ldots \ldots \ldots \ldots \ldots \ldots \ldots \ldots \ldots \ldots$

2 Representation of experimental set-up...................................... 31

3 Proportion of trials across treatment groups in which urine was released............. 32

4 Proportion of trials across treatment groups in which mating attempt were observed.... 33

5 Mean duration and number of urine release events for all males and females across treatment groups............................................. 34

6 Mean values of current generation duration for males and females in the

four experimental treatment groups.................................... 35

7 Mean number of currents generated by males and females from each treatment

group per trial............................................... 36

8 Two-dimensional plot of correspondence analysis of behavior, urine release, and current generation for male crayfish from the $\mathrm{I}+\mathrm{G}$ treatment group..... 37

9 Two-dimensional plot of correspondence analysis of behavior, urine release, current generation for the female crayfish from the $\mathrm{I}+\mathrm{G}$ treatment group.... 38

Table

1 Ethogram of behaviors analyzed with abbreviations used in correspondence

analysis 


\section{INTRODUCTION}

Communication as defined by E.O. Wilson (1975) is an action by an organism that alters the probability of behavior in another organism in an adaptive fashion. Enquist (1985) defines communication by explaining its opposite: if there is no communication taking place, there is no correlation between the sender's and receiver's behavior. Finally, Bradbury \& Vehrencamp (1998) argue that information exchange must benefit both the sender and the receiver to be called communication. In all of these definitions, the sending animal has control over when, where, and/or how a signal is released into the environment. This concept of communication is refined by Maynard Smith \& Harper (2004) who differentiated a cue from a signal. While a cue still provides information, it is not under the direct control of the sender. Signaling and the stimulus energies in signals can be used in a variety of behavioral settings including predator-prey interactions, mating situations, social behavior, and competition.

Social communication is used by numerous species to convey signals that are important for structuring behavioral interactions. Signals in social settings can provide information on aggression and fear (electric fish- Crawford et al. 1986; collembolan- Nilsson \& Bengtsson 2004), reproductive receptiveness (rotifers- Snell \& Rico-Martinez 1996; copepods- Lonsdale et al. 1998; rock shrimp- Diaz \& Thiel 2004; insects- Leslie 2005; marmosets- Zielger et al. 2005), as well as genetic familiarity (rodents- Johnston 2003; tamarins- Miller et al. 2003). This information can be conveyed by visual, mechanical, and/or chemical signals and is utilized by solitary and social species alike (Siebeck 2004; Miller 2006; Nascimento et al. 2005; Kölliker et al. 2005).

The use of chemical in aggressive encounters has been the subject of a number of recent studies. In particular, social communication has been studied extensively in decapod crustaceans 
(Caldwell \& Dingle 1979; Breithaupt \& Atema 1993; Snyder et al. 1993; Bergman et al. 2003;

Stebbing et al. 2003; Delgado-Morales et al. 2004; Raethke et al. 2004). Dominant state and aggression level have been shown to be communicated through chemical means in numerous decapod species including the American lobster, mantis shrimp, and many species of crayfish (Caldwell \& Dingle 1979; Karvanich \& Atema 1998a; Bergman \& Moore 2005). Breithaupt \& Atema (1993) found that the American lobster actively used urinary signals in male-male agonistic interactions. Karavanich \& Atema (1998b) showed this urine release could be used for individual recognition as well. Zulandt Schneider et al. (2001) showed the same in O. rusticus, in which the males use urinary signals for individual and dominance status recognition in their opponents. These studies have begun to provide a clearer picture on the how sensory signals are generated and used during social behaviors in crustaceans (Delgado-Morales et al. 2004; Bergman et al. 2005).

In crayfish, the movement of a fan organ, pleopods, and gills, along with nephropore propulsion, can be used to generate flow fields. Breithaupt (2001) demonstrated that crayfish could change the flow regime immediately adjacent to themselves by generating directed water currents with various appendages. These currents have been shown to move in excess of $10 \mathrm{~cm} / \mathrm{s}$ and are often coupled with urine release in male-male agonistic encounters (Bergman et al. 2005). Specifically, crayfish release urine from their nephropores during social interactions and the presence of this chemical signal influences the outcome of the agonistic interaction (Zulandt Schneider et al. 1999; 2001; Zulandt Schneider \& Moore 2000; Bergman et al. 2005). By utilizing urine visualization techniques, it was shown that crayfish preferentially use urine in agonistic encounters (Bergman et al. 2005). 
While chemical and mechanical communications in male-male agonistic interactions in crayfish have been studied extensively, investigations into the role of these same signals in malefemale interactions have been ignored. In particular, it is possible that these signals play many different roles in male-female interactions. In one case, these signals likely function in a similar manner in male-male and male-female interactions conveying information on aggressive state or dominance status. They may also contain information on the gender of the sender: the crayfish Procambarus clarkii use their antennules to discriminate between male and female conspecifics (Ameyaw-Akumf \& Hazlett 1975). Finally, these signals could play a role in providing information on reproductive readiness or receptivity. In this case, the signals may provide multiple pieces of information to the receiver that is critical for successful reproduction. The chemical and mechanical signals could communicate the reproductive state of the sender, their willingness to mate, or may even provide information that is used in mate choice. In decapod crustaceans, chemical communication has been implicated in reproductive signaling. Bushmann \& Atema (2000) and Snyder et al. (1993) demonstrated the use of chemical signals in mate location by the American lobster. Rathke et al. (2004) and Stebbing et al. (2003) also implicated chemical communication during reproductive activities for the spiny lobster and the signal crayfish, respectively. Dunham \& Oh (1992) showed gender identification through chemical means in the crayfish Procambarus clarkii, while Hazlett (1985) demonstrated both gender and sexual condition identification in Orconectes virilis.

The crayfish, Orconectes rusticus, is an excellent model to study the role of urinary and mechanical signals in both aggressive and potential mating situations during male-female communication. In this species of crayfish, both males and females have reproductive and nonreproductive forms. In addition, there are subtle differences in the timing of the male and female 
moult between reproductive forms that allows for investigation of communication between individuals of the differing reproductive forms. For example, the timing of reproductively allowed us to pair a reproductive individual with a non-reproductive individual to investigate differences in communication and behavioral strategies.

Since it is clear that urine release by crayfish is important in social interactions between males and that fluid flow can influence behavior (Zulandt Schneider et al. 1999; 2001; Breithaupt \& Egar 2002; Bergman et al. 2003; 2005; in prep.), we are interested in the role of chemical and mechanical signals during male-female interactions. Specifically, we wanted to compare the role of these signals in altering agonistic and mating behavior in four different types of male-female pairings. The first pairing consisted of a non-reproductive male coupled with a non-reproductive female. The last pairing consisted of a male and female that were both reproductively active. The other pairings were a mix of one reproductive and one nonreproductive individual. This experimental design allowed us to test the following questions: 1) Are urinary and mechanical signals used during male-female interactions, 2) If so, during what types of behavioral activities are these signals used, and 3) Does the reproductive state of both the male and female involved affect the use of these signals? 


\section{MATERIALS AND METHODS}

$\underline{\text { Animals }}$

Crayfish, Orconectes rusticus, were collected from two habitats and housed in two laboratory settings. From June to August 2005, male and female crayfish were collected from Maple Bay in Burt Lake, Michigan. Intermoult, sexually active and inactive crayfish were physically and socially isolated in flow-through tanks supplied with fresh lake water. Crayfish were housed at the University of Michigan Biological Station (UMBS) in semi-natural conditions, where they were exposed to natural light and temperature fluctuations. Crayfish diet consisted of detrital material introduced from the circulating lake water. In late summer and early fall (August - October 2005), crayfish were collected from Portage River, Wood County, Ohio. During this time, crayfish were housed in an environmental chamber at Bowling Green State University (BGSU) with regulated temperature $\left(21^{\circ} \mathrm{C}\right)$ and light:dark cycle $(14: 10)$. Crayfish were fed one commercial rabbit pellet three times per week. Under both conditions, crayfish were physically and socially isolated for a minimum of one week prior to use in behavioral trials to eliminate all effects from previous social interactions (Karavanich \& Atema 1998b). Crayfish interacted only with a partner from the same origin (UMBS or BGSU) to negate any differences due to place of origin that might have been present. Statistical analysis comparing behavior and urine release between trials of crayfish in identical reproductive forms from differing origins showed no significant differences (ANOVA; male: $N=39, F=2.151, P=0.1125$; female: $N=$ $39, F=1.068, P=0.3760)$. Thus, crayfish were grouped for final statistical analysis regardless of origin. Additionally, Bergman et al. (in prep.) showed that under stagnant conditions, the two populations of crayfish from BGSU and UMBS did not differ behaviorally. 


\section{$\underline{\text { Identification of reproductive status }}$}

Both male and female crayfish were classified according to their reproductive state based on their external morphology. Form II (non-reproductive) males were present during the summer, when mating does not typically occur (Berrill \& Arsenault 1984). They were characterized as having reduced ischial hooks and cornified stylets that are shorter and thicker than those of form I (reproductive) males (Crocker \& Barr 1968; Hobbs 1974; Fig. 1). Form I males (Fig. 1) were present from late summer to spring (Crocker \& Barr 1968; Hobbs 1974; Berrill \& Aresenault 1982). They were distinguished by their sharply pointed copulatory stylets as well as larger, more defined ischial hooks (Crocker \& Barr 1968; Hobbs 1974).

Females without glair were considered to be reproductively inactive and were present between May and September (Holdrich 2002). Females became sexually active in the early fall (Berrill \& Arsenault 1984). Glair glands became visible during this stage and could be seen as a whitened tissue on the underside of the female's tail (Holdrich 2002).

\section{Experimental treatments}

To elucidate any potential differences between current production, urine release and social behavior as a consequence of the different reproductive states in crayfish, four different experimental combinations were used in our behavioral studies $(N=$ number of urine positive trials out of the total number of trials run, see conditions for a urine positive trial below). Hereafter, these are referred to as treatments:

- II + N - non-reproductive (form II) male paired with non-reproductive (№n-glair) female; $N=11$ out of 16 trials 
- I + N - reproductive (form I) male paired with non-reproductive (on-glair) female; $N$ $=6$ out of 17 trials

- II $+\mathrm{G}-$ non-reproductive (form II) male paired with a reproductive (Glair) female; $N$ = 12 out of 18 trials

- I $+\mathrm{G}-$ reproductive (form I ) male paired with a reproductive (Glair) female; $\quad N=21$ out of 22 trials

For experimental treatments involving crayfish in both their reproductive or nonreproductive forms, crayfish were size-matched within $10 \%$ for carapace length and weight (Daws et al. 2002). When possible, chelae length was also matched within $10 \%$. Due to morphological differences in the length of the chelae in reproductively active males, size matching became difficult. For trials using form I males, chelae were no more than $30 \%$ larger then the chelae of the female crayfish. Mean $( \pm$ SEM) carapace length, chelae length and weight of all crayfish was as follows; carapace $3.72 \pm 0.050 \mathrm{~cm}$, chelae $3.26 \pm 0.084 \mathrm{~cm}$, and weight $17.59 \pm 0.756 \mathrm{~g}$. The number of trials in each group was limited by the total number of animals found during each season. A total of 146 animals were used during the course of the experiment, with each crayfish used only once. Crayfish were returned to the field after all effects of experimentation were absent, which usually occurred after a moult.

\section{Experimental Set-up}

The experimental setup, including tank, cameras, and black lights can be seen in Fig. 2. A glass aquarium $(23 \times 24 \times 23 \mathrm{~cm})$ was positioned centrally on a wooden and plexiglas stand. A moveable digital video camera (Canon XL-1) was used in front of the tank to focus on the anterior nephropore region of the two crayfish to capture urine release. A second stationary 
camera (Sony DCR-TRV900) was positioned underneath the tank for a second view of urine release, as well as to capture social behavior and current generation (see below). The cameras were temporally synchronized using a laser flash which was simultaneously recorded on both videos. Two black lights (15 W-GE \#F15T8), mounted above the tank, were used to maximize the illumination of dye released with the urine (see urine visualization techniques). In addition, two slide projectors (Kodak Ektra Graphic IIIA) were placed roughly $70 \mathrm{~cm}$ from the tank (Fig. 2). These were used to pass two thin beams of light through the tank to create a level plane of light $1.25 \mathrm{~cm}$ above the base of the tank. The plane of light illuminated particles that were moved due to crayfish maxilliped movements, gill action, or by urine projection from the nephropores. The light plane was created by inserting slides that had a thin horizontal slit $(\sim 15 \mu \mathrm{m})$ into the slide projectors which were placed on either side of the tank. Trials were performed in a darkened room with the black lights and slide projectors as the only sources of light. Test tanks were cleaned and filled with fresh water in between each trial to remove any residue from the previous trial. This setup, for differential particle illumination velocimetry (DPIV) and urine release detection, was similar to the design of Breithaupt \& Ayers $(1996 ; 1998)$ and Bergman et al. (2005).

In each trial, the male was marked with correction fluid on the ventral and dorsal sides of the chelae for identification during analysis. This type of marking method has been previously used and does not alter any of the behavioral outputs of the crayfish. For each trial, two sizematched, naïve crayfish (one male and one female) were separated visually, mechanically, and chemically and allowed to acclimate in the test tank for 15 minutes. The divider between the crayfish was then removed and the crayfish were allowed to interact for 20 minutes. Each trial was recorded from front and bottom views to provide a close analysis of all behaviors. 


\section{Urine Visualization-Injection Technique}

We adopted a technique tested by Breithaupt \& Eger (2002) and perfected by Bergman et al. (2005) to visualize urine release during male-female interactions. A 3 ppt sodium fluorescein (Sigma F-6377) solution dissolved in crayfish ringers ( $205 \mathrm{mmol} / \mathrm{L} \mathrm{NaCl}, 5.4 \mathrm{mmol} / \mathrm{L} \mathrm{KCl}, 13.5$ $\mathrm{mmol} / \mathrm{L} \mathrm{CaCl}_{2}, 5.6 \mathrm{mmol} / \mathrm{L} \mathrm{MgCl}_{2}$, and $2.4 \mathrm{mmol} / \mathrm{L}$ HEPES) was injected at a dose of $0.01 \mathrm{~mL}$ per gram body mass into the pericardial region of the crayfish. Preparation for injection entails drying a portion of the carapace followed by placement of a small strip of labelling tape over the injection site (dorsal carapace). A $1 \mathrm{~mL}$ syringe with a 26.5 gauge needle was used to inject the dye solution through a pierced hole in the carapace. The needle was then removed and an additional piece of tape and superglue was placed over the needle hole. After a male and female crayfish were injected, they were allowed a one to four hour acclimation period (Breithaupt \& Eger 2002; Bergman et al. 2005). 14 out of 160 crayfish died during this procedure. Pilot studies $(N=8, P=0.579)$ and subsequent behavioral analysis showed that this handling procedure and injection of dye did not significantly alter crayfish social interactions.

\section{$\underline{\text { DPIV }}$}

\section{Current Visualization}

Neutrally buoyant particles were prepared with ABS stock material (acrylonitrile butadiene styrene; GE Polymerland \#FCCS0CP2002RBJ; 1.10 sp. gr. @ $23^{\circ} \mathrm{C}$ ). The material was frozen with liquid nitrogen and ground using a coffee grinder (Braun \#KSM2). The resulting particles were then sorted using a series of mesh sieves. One teaspoon of the ground particles ( dia. $<0.006 \mathrm{~cm}$ ) was added to the test tank. After each trial, the tank was rinsed, refilled with 
water, and new particles were added. A comparison of crayfish social interactions in the presence of particles to other studies on behavior without particles showed that the experimental conditions caused no observable changes in the crayfish fight structure (Zulandt Schneider et al. 1999; 2001; Bergman et al. 2003; 2005).

\section{Current analysis}

Flow fields were analyzed by tracking particles on a video monitor. Current generation by the male and female crayfish could be seen by movement of particles away from the individual at either the anterior or posterior end. Anterior currents were generated by maxilliped movement, and possibly by gill processes or nephropore release of urine. Projection currents were currents moving away from the tail and were generated by the tail and/or the modified swimmerets. Start and stop times of currents were recorded for both the male and female. Social Behavior Analysis

Social behaviors were examined and correlated with communication behaviors including current generation and urine release. A behavioral analysis was performed similar to Bergman et al. (2005) with an additional analysis of mating behavior as described in Mason (1970) to quantify the social behavior of the crayfish. Social behaviors are characterized for every second by using an ethogram (Table 1). Mating was designated as a single behavior in which the submission female was considered the initiation of mating while release or escape of the female was considered the conclusion.

\section{$\underline{\text { Statistical Analysis }}$}

To determine if treatment group had an effect on the presence of a urine release event, a chi-squared test was performed on the number of trials in which urine release was visualized 
across the four groups. A trial was considered urine positive if at least one animal released urine at any point during the 20 minutes of interaction. All subsequent statistical analysis was preformed on the urine positive trials. To determine if treatment had an impact on the presence of mating behavior, a chi-square analysis was conducted. When significance was detected using the chi-square, specific differences in mating attempts within reproductive pairings were investigated using a test for multiple comparisons for proportions contingency table that allows for testing analogous to the Tukey or Student-Newman-Keuls tests ( $\left(\mathrm{q}_{0.05, \infty, 4}=3.633\right.$; Zar 1999). Dye released with the urine was recorded in terms of gender, total duration, and number of urine release events per trial for each crayfish. A (4 x 2) two-way factorial MANOVA, with treatment group and gender, was used to test for significant differences between the urine releases and number of urine releases. A separate $(4 \times 2 \times 2)$ three-way factorial MANOVA, with treatment group, gender, and current type, was performed to test for differences between duration and number of currents.

Correspondence analysis was performed to look for the temporal similarities in social behavior, urine release, and current generation (van der Heijden et al. 1990; Moyaho et al. 1995; Bergman et al. 2005). Correspondence analysis results were arranged into a graphical representation of social behavior, urine release, and current generation on a single graph. For the purpose of publication, these 3-D graphs are printed in two dimensions. The origin of the graph represented the expected value (mean profile) for all acts. The closer a point (social behavior, current or urine release) was to the origin; the more similar it was to the mean profile. The closer together two points were on the graph, the more correlated in time those acts were. The proximity of all points on a graph showed the degree to which the acts were synchronized in 
time. All statistical tests were performed using Statistica 6.0 and significance is set at $\mathrm{p}<0.05$. All values reported below are mean \pm standard error of the mean. 


\section{RESULTS}

$\underline{\text { Urination rates }}$

In the total of 73 trials run during the course of this experiment, either the male and/or female crayfish released urine in 50 of those trials. Urine release was not equally distributed across reproductive pairings (Fig. $3 ; \chi^{2}=16.12, d f=3, P<0.01$ ). Urine release was significantly higher when both crayfish were in reproductive forms: $I+G$ treatment group $(91 \%)$, II + G group $(67 \%), \mathrm{II}+\mathrm{N}(69 \%)$, and $\mathrm{I}+\mathrm{N}$ group $(35 \% ; \mathrm{q}>5.12$ in all significant comparisons). In addition, the number of urine releases was significantly lower when the female crayfish was not in glair and the male was in reproductive form compared to the other three groups ( II+N, II $+\mathrm{G}, \mathrm{I}+\mathrm{G} ; \mathrm{q}>$ 5.1 in all significant comparisons).

\section{Mating behavior}

Mating behavior was observed only when both the male and female crayfish were in reproductive forms $(\mathrm{I}+\mathrm{G})$. Within this treatment group, mating attempts were seen in eight out of 21 trials $(38.1 \%)$ while none of the remaining groups $(\mathrm{II}+\mathrm{G}, \mathrm{I}+\mathrm{N}, \mathrm{II}+\mathrm{N})$ contained any mating behavior. Chi-square analysis showed a significant difference between groups with this distribution of mating behavior $\left(\chi^{2}=24, d f=3, P<0.001\right.$; Fig. 4$)$.

\section{$\underline{\text { Urine Release }}$}

\section{Overall}

Trials with both crayfish in reproductive pairings $(\mathrm{I}+\mathrm{G})$ showed a significant increase in both the number and duration of urine releases (Fig. 5; Two-way MANOVA; $N=100, F=6.74$, $P<0.0001)$. Within all pairings, there was no significant difference in urine release or duration 
with respect to the gender of the signaller (Two-way MANOVA; $N=100, F=1.38, P=0.256$;

Fig. 5). Additionally, there was no significant difference in the interaction between treatment group and gender of the sender for either number of urine releases or duration (Two-way MANOVA; $N=100, F=1.01, P=0.420$; Fig. 5).

Total Duration of Urine Release

Males and females within the $\mathrm{I}+\mathrm{G}$ treatment group demonstrated significantly longer durations (Mean \pm S.E.; males: $19.9 \pm 5.49 \mathrm{~s}$, female: $23.1 \pm 3.50 \mathrm{~s} ; P<0.05$ ) than all releases by other individuals except females in II $+\mathrm{G}$ trials $(17.7 \pm 5.85 \mathrm{~s} ; P>0.05$; Fig. 5A). Males and females released urine for similar amounts of time when compared within each trial $(P>0.05$; Fig. 5A).

\section{Number of Urine Release Events}

Males and females within reproductive $(\mathrm{I}+\mathrm{G})$ trials (males: $3.56 \pm 0.45$, females: $3.58 \pm$ 0.41) released urine more frequently. Females from these trials released urine significantly more often than females from all other treatment groups $(P<0.05$; Fig. 5B). Males from the $\mathrm{I}+\mathrm{G}$ treatment group released urine a significantly greater number of times when compared to all other males $(P<0.05)$. Within each treatment group, no statistical differences were found between males and females for the total number of urine release events $(P>0.05$; Fig. 5B).

\section{Current Production}

Overall

Trials with both crayfish in reproductive forms $(\mathrm{I}+\mathrm{G})$ showed a significant increase in the duration of currents produced (Three-way factorial MANOVA; $N=100, F=24.8, P<0.001$; Fig. 6). Crayfish, regardless of gender, produced longer anterior currents than posterior currents 
across all reproductive pairings (Three-way factorial MANOVA; $N=100, F=37.1, P<0.001$; Fig. 6). There was no overall significant difference in the duration of currents between the genders $(P=0.12)$, although there were significant interactions between gender and current type $(F=5.40, P<0.006)$, reproductive form and current type $(F=24.6, P<0.001)$, and gender, reproductive pairing, and current type $(F=2.88, P<0.01)$.

\section{Duration of Currents}

Total - Both males and females in the $\mathrm{I}+\mathrm{G}$ and II $+\mathrm{G}$ treatment groups generated currents for a significantly longer period of time per trial then the I+N and II $+\mathrm{N}$ groups (Fisher-LSD post hoc tests; $P<0.05$; Fig. 6A). Reproductive males interacting with reproductive females (I+G) generated currents for the greatest amount of time overall $(993.8 \pm 24.9 \mathrm{~s}$; Fisher-LSD post-hoc tests; $P<0.005$ ), while males in the II $+\mathrm{N}$ treatment group generated currents for the least amount of time $(176.1 \pm 31.6 \mathrm{~s} ; P<0.005)$. In addition, males in the $\mathrm{I}+\mathrm{G}$ treatment group generated currents for a significantly longer duration of time than the females within the same treatment group (Fisher-LSD post-hoc tests; $P<0.05$ ).

Posterior Currents - Few differences based on treatment type were seen in the generation of posterior currents. However, females from the $\mathrm{I}+\mathrm{G}(188.3 \pm 45.3 \mathrm{~s}$; Fisher-LSD post-hoc tests; $P<0.05)$ and $\mathrm{II}+\mathrm{G}(264 \pm 66.8 \mathrm{~s} ;$ Fisher-LSD post-hoc tests; $P<0.05)$ treatment groups spent significantly more time generating posterior currents then their male counterparts (Fig. 6B).

Anterior Currents - Both the male and female crayfish in the $\mathrm{I}+\mathrm{G}$ treatment group generated anterior currents for a significantly longer period of time per trial then individuals from all other treatments (Fisher-LSD post-hoc tests; $P<0.01$; Fig. 6C). Males and females in the non-reproductive treatments $(\mathrm{II}+\mathrm{N})$ generated the least amount of anterior currents (FisherLSD post-hoc tests; $P<0.05$; Fig. 6 C). 


\section{Number of Currents Generated}

Total - There were no consistent significant differences in the number of currents generated per trial across treatment groups and between genders (Fig. 7C). Males in the $\mathrm{I}+\mathrm{G}$ treatment group had the lowest total number of currents generated $(9.38 \pm 1.49)$. The females in the $\mathrm{I}+\mathrm{G}$ treatment group generated a similar number of currents $(13.2 \pm 1.72)$ as well as the males in $\mathrm{II}+\mathrm{G}$ trials $(12.4 \pm 1.57$; Fisher-LSD post-hoc tests; $P>0.05)$. The only significant difference was seen between the prior three and the females from the II $+\mathrm{G}$ treatment group (19.5 \pm 1.74 ; Fisher-LSD post-hoc tests; $P<0.05$ ).

Posterior Currents - Differences in the number of posterior currents generated by males and females were significant in the $\mathrm{I}+\mathrm{G}$ trials (Fisher-LSD post-hoc tests; $P<0.05$ ), with females generating more posterior currents $(6.76 \pm 1.29)$ then males $(2.95 \pm 0.91)$. On average, females in the II $+\mathrm{N}(10.8 \pm 2.44)$ and $\mathrm{II}+\mathrm{G}(11.2 \pm 1.17)$ generated the most posterior currents (Fig. 7B).

Anterior Currents - Males and females generated the same number of anterior currents per trial for all treatment groups (Fisher-LSD post-hoc tests; $P>0.05)$. Males in the $\mathrm{I}+\mathrm{N}(9.17 \pm$ $2.14)$ and $\mathrm{II}+\mathrm{G}(8.67 \pm 1.31)$ trials generated more anterior currents than males in the II $+\mathrm{N}(4.09$ \pm 0.77 ) trials (Fisher-LSD post-hoc tests; $P<0.05$; Fig. 7A).

\section{Correspondence Analysis}

Results from the correspondence analysis showed temporal similarities between current generation, urine release, and social behavior for both males $(P<0.001)$ and females $(P<0.001)$ within the $\mathrm{I}+\mathrm{G}$ treatment group (Figs. 8,9). For both males and females, a correlation exists between pre-urine (PreU), urine (U), and post-urine (PostU) release with anterior currents (A) 
and chelae contact (CC) behavior. For this set of behaviors, the female correspondence was stronger than that of the males. Correlations were also found between chelae holding $(\mathrm{CH})$ behavior and anterior current generation (PreU:A, U:A, PostU:A) for males (Fig. 8). Urine release in the absence of current generation (PreU:N, U:N, PostU:N), and mating (M) behavior were correlated for both the males and females (Figs. 8,9). Correspondence analysis could not be completed on the II $+\mathrm{N}, \mathrm{I}+\mathrm{N}$, and $\mathrm{II}+\mathrm{G}$ treatment groups due to a lack of observed social behaviors, urine release, and current generation within each treatment. 


\section{DISCUSSION}

Our results show that the chemical and mechanical communication between male and female crayfish was altered by the reproductive state of the individuals involved in the interaction. Use of urinary signals, as indicated by number and duration of urine release events, was significantly increased when crayfish were in their reproductive state (Figs. 3 and 5). The use of currents was also significantly increased in the reproductive state (Figs. 6 and 7). It appears as if both of these communicative behaviors were correlated in time with chelae contact, chelae holds and mating events in both males and females (Figs. 8 and 9). Finally, mating behavior was only observed in trials were both crayfish were in their reproductive forms (Fig. 4) and in trials where chemical and mechanical communication was the greatest.

\section{Chemical signaling through urine release}

These results strongly suggest that urinary signals are a form of communication that is important during reproductive interactions and this communication is used for some aspect of mate choice. If this conclusion is true, we would predict that there would be an increase in chemical communication when both crayfish are in reproductive forms and potentially choosing mates. In those trials with both crayfish reproductively active, almost all parings resulted in urine release from both crayfish (Fig. 3). The most parsimonious explanation for these results is that crayfish were using chemical signals to provide information about their gender and/or reproductive state or to even provide cues used to assess factors involved in mate choice.

It is possible that additional information could be communicated through visual signals or through body odors transported by currents. Rahman et al. (2001) showed reproductive 
recognition between female big-clawed snapping shrimp and conspecific males. However they did not fully explore the sensory mechanisms for this recognition. Gender recognition has also been demonstrated in the red swamp crayfish (Procambarus clakii). Male crayfish win more bouts and evict more non-reproductive females from their shelter than they do reproductive females (Figler et al. 2005). As previously, these studies did not examine how information on reproductive status was communicated or received. Zulandt-Schneider et al. (2001) and Bergman et al. (2005) firmly established that urinary signals are important during male-male social interactions. These findings, combined with the results in this study, suggest that crayfish can recognize reproductive status and/or reproductive readiness through the use of urinary signals and alter their subsequent behavior by increasing the subsequent use of urinary and mechanical signals during interactions between reproductive individuals.

There are a variety of signals that could be used by individuals to gather information about their opponents. Crayfish may be communicating information through the temporal use of urinary or mechanical signals. Aspects of the timing of release of urine or the coupling of urine release with different behaviors may be signaling reproductive state. Our study between male and female crayfish and a similar study investigating communication between male crayfish (Bergman et al. 2005; Figs. 4, 5, 7, and 9 in that study) provide evidence that urine release is timed with both the generation of currents and social behaviors (Figs. 8, 9). Differences in urine release were related to social status; dominant crayfish used urinary signals more frequently and for longer durations than subordinate crayfish (Bergman et al. 2005). This indicates that the use of urine, as in number of release events and release duration, is variable and controllable. In both this study and the work presented here, urine release was temporally coupled with anterior 
current production and chelae contact or grabbing. Thus, it does not appear that female-male urine use is temporally distinct from urine use during male-male interactions.

Another potential source of information in the signals quantified here is the chemical composition of the urine being released. Although we have not quantified the chemical composition of the urine, Bergman \& Moore (2005) and Zulandt Schneider et al. (2001) have suggested that it is likely that the chemical composition of the urine is changing as a function of behavioral changes. These studies have suggested that the composition of urine is variable through time and that these changes can occur over the course of days which is the time frame over which social status also changes. Previous work in male-male interactions has shown that the presence of urinary signals influence social interactions and may indicate dominance status (Zulandt Schneider et al. 1999, 2001, Beithuapt \& Egar 2002). Hardege et al. (2002) has suggested that the composition of urine is the source of information for mating interactions in crabs. It is interesting to note that urine release was used in non-reproductive pairings in our study showing that these signals are used both in agonistic and mating interactions between male and female crayfish. All of this work taken in combination predicts that the composition of the urine is the probable source of information and that this composition changes as a function of reproductive status. Within the context of this study, urine release is probably used to communicate reproductive status, possibly used as a source of information to assess fitness of the individuals involved in communication, and could be used in mate choice.

There was no difference in the use of urinary signals between males and females in regard to number and duration of events (Fig. 5). Although the measures we quantified within this study showed no correlation with gender, it is not suggested that there were no differences in chemical composition of the urine. Other crustaceans do exhibit differences in the chemical 
composition of urine across gender. In shore crabs (Carcinua maenas) response to female urine was dependent upon the female's reproductive status, and males responded appropriately to precopula female odor even if the odor source was associated with an inappropriate object such as another male or an inanimate object (Hardege et al. 2002).

\section{Mechanical signaling through current generation}

In addition to differences in chemical signals, there were significant differences in the use of mechanical signals in the form of currents. Although the number of currents generated did not differ between treatment groups, reproductive pairings resulted in a dramatic increase in the duration of the anterior currents (Figs. 6, 7). Since reproductively-active crayfish are changing how they use currents during social interactions, it is possible that currents were used to send information or to disperse urine. Crayfish switched from short bouts of both anterior and posterior currents to longer durations of anterior currents when they become reproductive. Previous work has correlated the use of anterior currents with urine release in male-male interactions (Bergman et al. 2005). The increase in urine release in the $\mathrm{I}+\mathrm{G}$ treatment group may be a determining factor in the increase in current generation within that group as well. Crayfish may have increased the duration of the anterior currents in order to have more effective release and transport of urine during potential mating interactions. We suggest that the currents were not providing information per se, but were facilitating the role of urine as a signal.

\section{Correlation of urine release, current generation, and behavior}

By combining our three measures (social behavior, current generation, and urine release) into a single analysis, it appears as if there are set behavioral patterns correlated with urinary 
signals during social interactions. Correspondence analysis (Figs. 8, 9) examines the temporal similarities between agonistic or mating behavior, urine release, and current generation. In our study, only the pairing with two reproductively active crayfish ( $+\mathrm{G}$ treatment group) demonstrated enough urine release, current generation, and agonistic or mating behavior to appropriately complete this statistical analysis. Our analysis indicates that male and female behaviors were correlated in a similar fashion to that seen during male-male interactions by Bergman et al. (2005). The tightest correlation for both male and females was present with anterior current generation just prior to, during, and just after urine release while the two opponents were in chelae contact. This supports the conclusion that the anterior current was used as a mechanism for urine transport.

In a similar fashion, chelae holding by reproductive males was also correlated with urine release during anterior current generation. These results are similar to Belanger \& Moore (2006) who found an increase in chelae contact by reproductive males compared to non-reproductive males in response to a female odor source. When demonstrating urine release, crayfish were typically facing each other with chelae touching their opponent. This position, along with an anterior projection current, may have allowed for the most effective transmission of a chemical signal through the urine. During chelae contact and urine release, the crayfish pair usually limited their movements to antennule whips which have been shown to be an active sampling technique in gender recognition crayfish (Dunham \& Oh 1992).

\section{$\underline{\text { Summary }}$}

These results demonstrate the ability of crayfish to change the use of mechanical and chemosensory communication as a function of their reproductive status. In particular, the same 
types of signals used during male-female agonistic interactions are altered in male-female reproductive interactions. The male-female signaling behavior that has been quantified in detail here is similar to other work done on male-male crayfish chemical and mechanical signaling (e.g. Bergman et al. 2005; Breithaupt \& Eger 2002). The distinction with this work is the role of these signals in reproductive communication. Our results support the idea that urine is a chemical signal that is possibly used for identification of reproductive status, receptiveness, and even possibly used to assess information for mate choice. In particular, it is the alternation in reproductive forms that are correlated with differences in sensory signaling, with the reproductive crayfish preferentially increasing current generation and urine release. Finally, it is only in those trials that urine was released that mating was observed. This study shows that behavioral and communicational differences do exist between the reproductive forms for both male and female crayfish, and that urine is a likely source of information during reproductive behavior. 


\section{REFERENCES}

Ameyaw-Akumfi, C. \& Hazlett, B. A. 1975. Sex recognition in the crayfish Procambarus clarkii. Science, 190, 1225-1226.

Belanger, R. M. \& Moore, P. A. 2006. The use of the major chelae by reproductive male crayfish (Orconectes rusticus) for discrimination of female odours. Behavior, in press.

Bergman, D. A., Kozlowski, C. P., McIntyre, J. C., Huber, R., Daws, A. G. \& Moore, P. A. 2003. Temporal dynamics and communication of winner-effects in the crayfish, Orconectes rusticus. Behavior, 140, 805-825.

Bergman, D. A., Martin, A. L. \& Moore, P. A. 2005. Control of information flow through the influence of mechanical and chemical signals during agonistic encounters by the crayfish, Orconectes rusticus. Animal Behavior, 70, 485-496. doi: 10.1016/j.anbehav.2004.11.021.

Bergman, D. A. \& Moore, P. A. 2005. Prolonged exposure to social odours alters subsequent social interactions in crayfish (Orconectes rusticus). Animal Behavior, 70, 311-318. doi: 10.1016/j.anbehav.2004.10.026.

Bergman, D. A., Redman, C., Fero, K. C., Simon, J. L. \& Moore, P. A. The impacts of flow on fight dynamics and urine release of crayfish, Orconectes rusticus and Orconectes virilis, a behavioral test of the matched filter hypothesis. In preparation.

Berrill, M. \& Arsenault, M. 1982. Spring breeding of a northern temperate crayfish, Orconectes rusticus. Canadian Journal of Zoology, 60, 2641-2645.

Berrill, M. \& Arsenault, M. 1984. The breeding behavior of a northern temperate orconectid crayfish, Orconectes rusticus. Animal Behavior, 32, 333-339.

Bradbury, J. W. \& Vehrencamp, S. L. 1998. Principles of Animal Communication. Sundreland, MA: Sinauer Associates Inc., Publishers. pp 2-6, 279-315. 
Breithaupt, T. 2001. Fan organs of crayfish enhance chemical information flow. Biological Bulletin, 200, 150-154.

Breithaupt, T. \& Atema, J. 1993. Evidence for the use of urine signals in agonistic interactions of the American lobster. Biological Bulletin, 185, 318.

Breithaupt, T. \& Ayers, J. 1996. Visualization and quantitative analysis of biological flow fields using suspended particles. In: Zooplankton: Sensory Ecology and Physiology (Ed. By P.H. Lenz, D.K. Hartline, J.E. Purcell \& D.L. Macmillian), pp 117-129. Amsterdam: Gordon \& Breach.

Breithaupt, T. \& Ayers, J. 1998. Visualization and quantification of biological flow fields through video-based digital motion-analysis techniques. Marine Freshwater Behavior and Physiology, 31, 55-61.

Breithaupt, T. \& Eger, P. 2002. Urine makes the difference: chemical communication in fighting crayfish made visible. Journal of Experimental Biology, 205, 1221-1231.

Bushmann, P. J. \& Atema, J. 2000. Chemically mediated mate location and evaluation in the lobster, Homarus americanus. Journal of Chemical Ecology, 26, 883-899.

Caldwell, R. L. \& Dingle, J. 1979. The influence of size differential on agonistic encounters in the mantis shrimp, Gonodactylus viridis. Behavior, 69, 255-264.

Crawford, J. D., Hagedorn, M. \& Hopkins, C. D. 1986. Acoustic communication in an electric fish, Pollimyrus isidori (Mormyridae). Journal of Comparative Physiology A: Neuroethology, Sensory, Neural and Behavioral Physiology, 159, 297-310.

Crocker, D. W. \& Barr, D. W. 1968. Handbook of the Crayfish of Ontario. University of Toronto Press. 
Daws, A. G., Grills, J. L., Konzen, K. \& Moore, P. A. 2002. Previous experiences alter the outcome of aggressive interactions between males in the crayfish, Procambarus clarkii. Marine and Freshwater Behavior and Physiology, 35, 1152-1161.

Delgado-Morales, G., Hernandez-Falcon, J. \& Ramon, F. 2004. Agonistic behavior in crayfish: the importance of sensory inputs. Crustaceana, 77, 1-24.

Diaz, E. R. \& Thiel, M. 2004. Chemical and visual communication during mate searching in rock shrimp. Biological Bulletin, 206, 134-143.

Dunham, D. W. \& Oh, J. W. 1992. Chemical sex discrimination in crayfish Procambarus clarkii: role of antennules. Journal of Chemical Ecology, 18, 2363-2372.

Enquist, M. 1985. Communication during aggressive interactions with particular reference to variation in choice of behavior. Animal Behavior, 33, 1152-1161. doi:10.1016/S00033472(85)80175-5.

Figler, M. H., Blank, G. S. \& Peeke, H. V. S. 2005. Shelter competition between resident male red swamp crayfish Procambarus clarkii (Girard) and conspecific intruders varying by sex and reproductive status. Marine and Freshwater Behavioral Physiology, 38, 237-248.

Hardege, J. D., Jennings, A., Hayden, D., Muller, C. T., Pascoe, D., Bentley, M. G. \& Clare, A. S. 2002. Novel behavioral assay and partial purification of a female-derived sex pheromone in Carcinus maenas. Marine Ecology Progress Series, 244, 179-189.

Hazlett, B. A. 1985. Chemical detection of sex and condition in the crayfish Orconectes virilis. Journal of Chemical Ecology, 11, 181-189.

van der Heijden, P. G. M., de Vries, H. \& van Hooff, J. A. R. A. M. 1990. Correspondence analysis of transition matrices, with special attention to missing entries and asymmetry. Animal Behavior, 40, 49-64. doi:10.1016/S0003-3472(05)80665-7. 
Hobbs Jr., H. H. 1974. Synopsis of the families and Genera of Crayfishes (Crustacea: Decapoda). Smithsonian Contributions to Zoology, 164, 1-32.

Holdrich, D. M. 2002. Biology of freshwater crayfish. Ames, Iowa: Iowa State University Press.

Johnston, R. E. 2003. Chemical communication in rodents: from pheromones to individual recognition. Journal of Mammalogy, 84, 1141-1162.

Karavanich, C. \& Atema, J. 1998a. Olfactory recognition of urine signals in dominance fights between male lobster, Homarus americanus. Behavior, 135, 719-730.

Karavanich, C. \& Atema, J. 1998b. Individual recognition and memory in lobster dominance. Animal Behavior, 56, 1553-1560. doi:10.1006/anbe.1998.0914.

Kölliker, M., Chuckalovcak, J. P. \& Brodie, E. D. 2005. Offspring chemical cues affect maternal food provisioning in burrower bugs, Sehirus cinctus. Animal Behavior, 69, 959-966. doi:10.1016/j.anbehav.2004.06.031.

Leslie, M. 2005. Scent of an insect. Science, 308, 28-29.

Lonsdale, D. J., Frey, M. A. \& Snell, T. W. 1998. The role of chemical signals in copepod reproduction. Journal of Marine Systems, 15, 1-12.

Mason, J. C. 1970. Copulatory behavior of the crayfish Pacifastacus trowbridgii (Stimpson). Canadian Journal of Zoology, 48, 969-976.

Maynard Smith, J. \& Harper, D. 2004. Animal signals. Oxford: Oxford University Press.

Miller, K. E., Laszlo, K. \& Dietz, J. M. 2003. The role of scent marking in the social communication of wild golden lion tamarins, Leontopitheus rosalia. Animal Behavior, 65, 795-803. doi:10.1006/anbe.2003.2105. 
Miller, P. J. O. 2006. Diversity of sound pressure levels and estimated active space of resident killer whale vocalizations. Journal of Comparative Physiology A: Sensory, Neural and Behavioral Physiology, 192, 449-459.

Moyaho, A., Eguibar, J. R. \& Diaz, J. L. 1995. Induced grooming transitions and open field behavior differ in high- and low-yawning sublines of Sprague-Dawley rats. Animal Behavior, 50, 61-72. doi:10.1006/anbe.1995.0221.

Nascimento, F. S., Hrncir, M., Tolfiski, A. \& Zucchi, R. 2005. Scraping sounds produced by a social wasp (Asteloeca ujhelyii, Hymenoptera, Vespidae). Ethology, 111, 1116-1125.

Nilsson, E. \& Bengtsson, G. 2004. Death odor changes movement pattern of a Collembola. Oikos, 104, 509-517.

Raethke, N., MacDiarmid, A. B. \& Montgomery, J. C. 2004. The role of olfaction during mating in the southern temperate spiny lobster Jasus edwardsii. Hormones and Behavior, 46, $311-318$.

Rahman, N., Dunham, D. W. \& Govind, C. K. 2001. Mate recognition and paring in the bigclawed snapping shrimp, Alpheus heterochelis. Marine and Freshwater Behavior and Physiology, 34, 213-226.

Siebeck, U. E. 2004. Communication in coral reef fish: the role of ultraviolet colour patterns in damselfish territorial behavior. Animal Behavior, 68, 273-282. doi:10.1016/j.anbehav.2003.11.010.

Snell, T. W. \& Rico-Martinez, R. 1996. Characteristics of the mate-recognition pheromone in Brachionus plicatilis (Rotifera). Marine and Freshwater Behavior and Physiology, 27, $143-151$. 
Snyder, M. J., Ameyaw-Akumfi, C. \& Chang, E. S. 1993. Sex recognition and the role of urinary cues in the lobster, Homarus americanus. Marine Behavioral Physiology, 24, 101-116.

Stebbing, P. D., Bentley, M. G. \& Watson, G. J. 2003. Mating behavior and evidence for a female released courtship pheromone in the signal crayfish Pacifastacus leniusculus. Journal of Chemical Ecology, 29, 465-475.

Wilson, E. O. 1975. Sociobiology. Cambridge, MA: Belknap Press of Harvard University. pp. 176-241.

Zar, J. H. 1999. Biostatistical Analysis. $4^{\text {th }}$ ed. Englewood Cliffs, New Jersey: Prentice Hill.

Ziegler, T. E., Schultz-Darken, N. J., Scott, J. J., Snowdan, C. T. and Ferris, C. F. 2005. Neuroendocrine response to female ovulatory odors depending upon social condition in male common marmosets, Callithrix jacchus. Hormones and Behavior, 47, 56-64.

Zulandt Schneider, R. A. \& Moore, P. A. 2000. Urine as a source of conspecific disturbance signals in crayfish Procambarus clarkii. Journal of Experimental Biology, 203, 765-771.

Zulandt Schneider, R. A., Huber, R. \& Moore, P. A. 2001. Individual and status recognition in the crayfish, Orconectes rusticus: the effects of urine release on fight dynamics. Behavior, 138, 137-153.

Zulandt Schneider, R. A., Schneider, R. W. S. \& Moore, P. A. 1999. Recognition of dominance status by chemoreception in the red swamp crayfish, Procambarus clarkii. Journal of Chemical Ecology, 25, 781-794. 


\section{APPENDIX A: FIGURES AND TABLES}
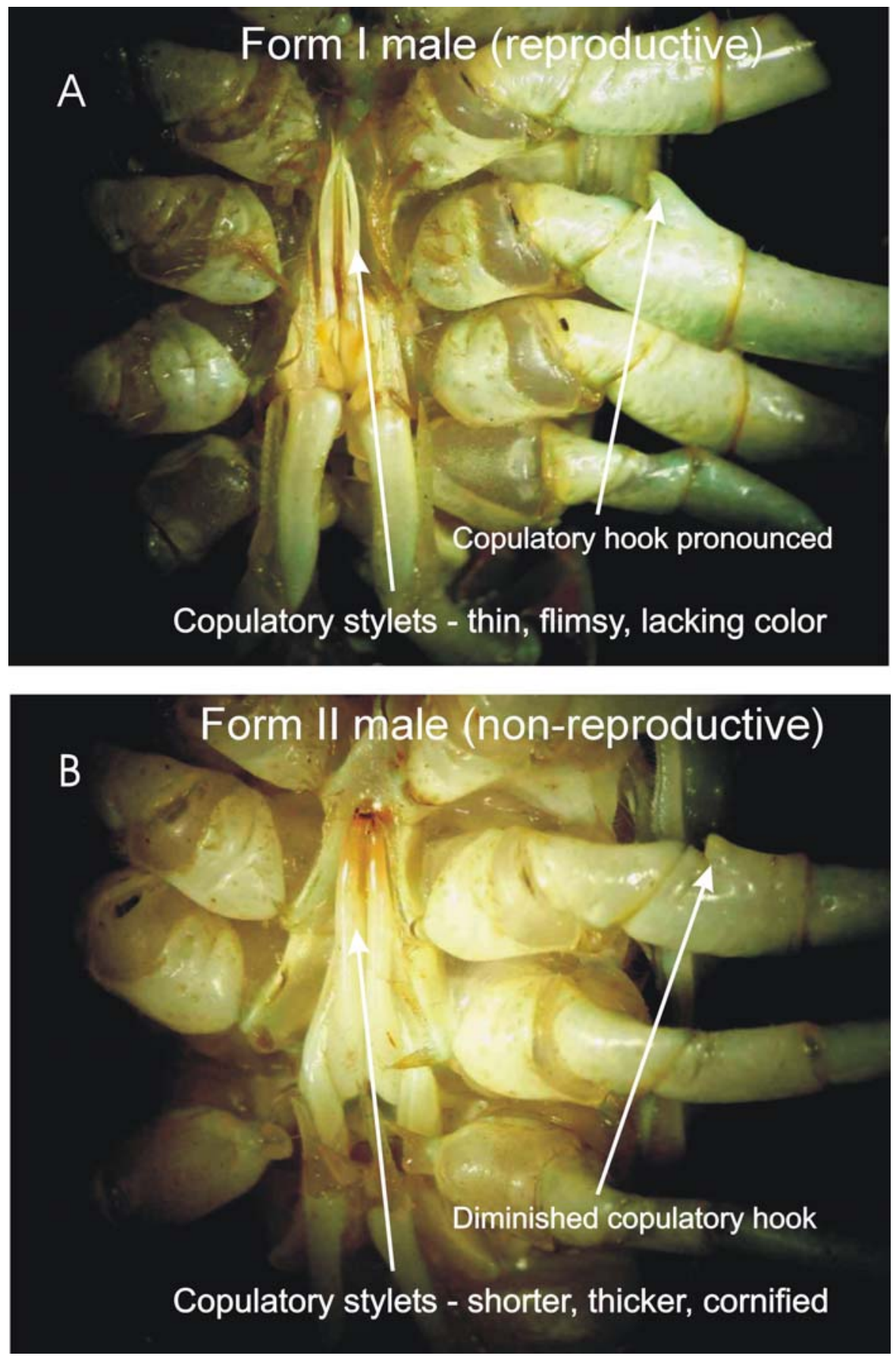

Figure 1. Dorsal view of male Orconectes rusticus, both in mating season (form I, A) and when non-reproductive (form II, B). Morphological differences can de distinguished in the copulatory (or ischial) hook on the second walking leg and in the modified stylets used in sperm transfer. 


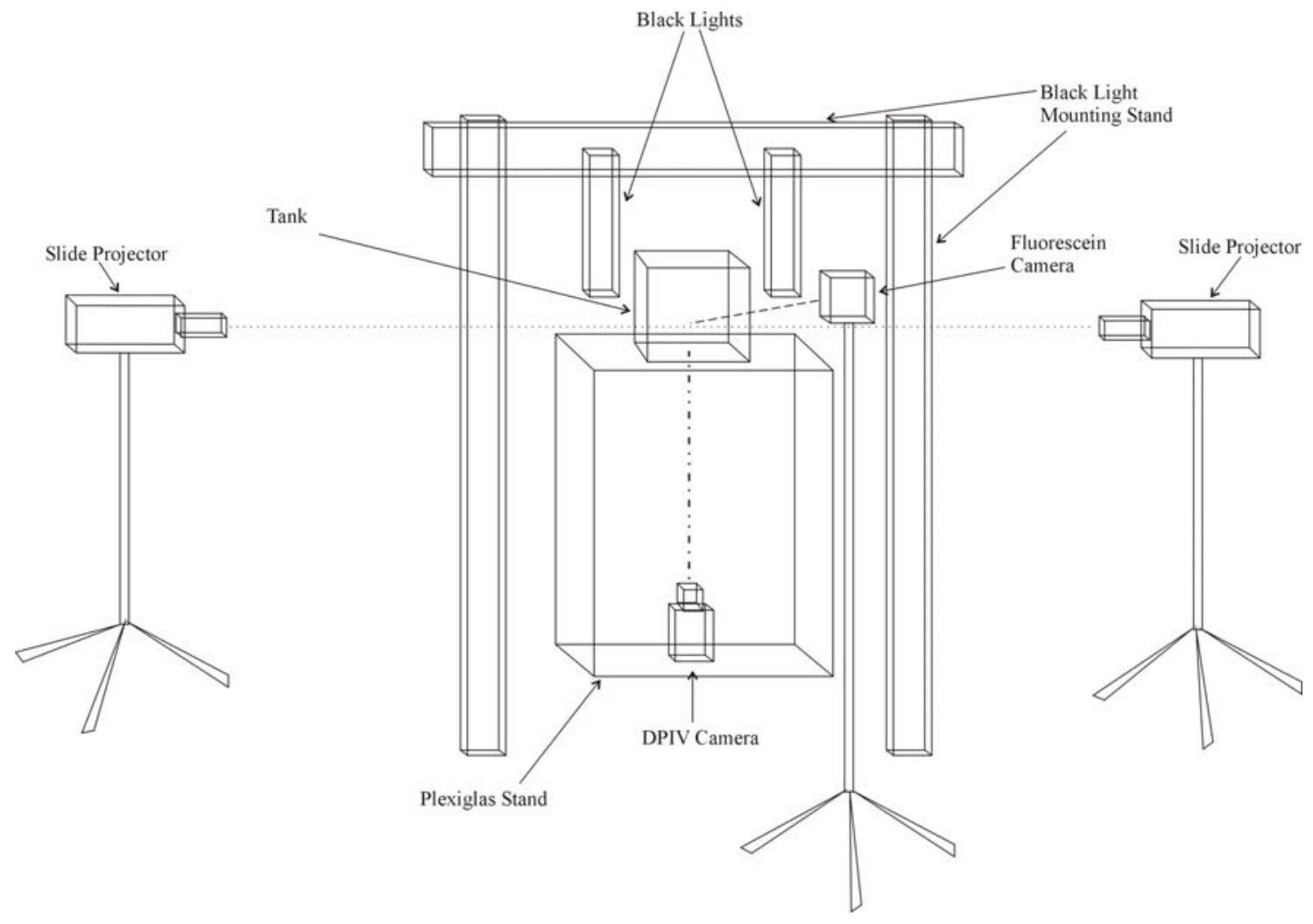

Figure 2. Schematic representing experimental set-up for urine and current visualization. Two digital video cameras were utilized to capture behavior, urine release, and current generation simultaneously. Blacklights, placed on the side of the tank, enhanced visualization of the fluorescein dye released with the urine. Slide projectors on the side were used to create a thin plane of light through experimental tank for visualization of mechanical signaling. Set-up modified from Bergman et al. (2005). 


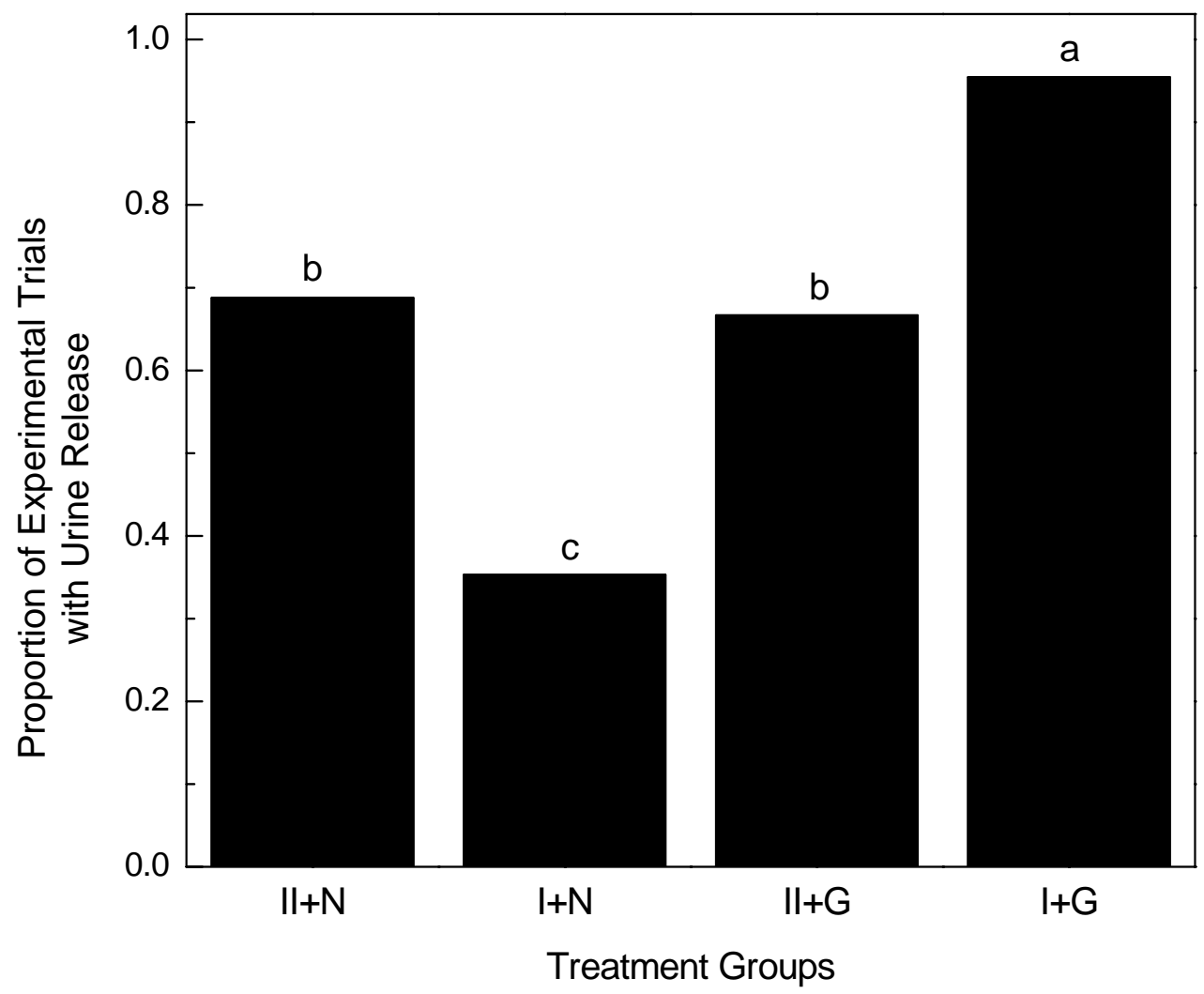

Figure 3. Proportion of experimental trials that resulted in urine release from either the male or female crayfish. Titles along the $\mathrm{x}$-axis represent the reproductive state of the male (first letters) and the female (second letters). Initial letter in the treatment groups refers to the reproductive status of males (I: reproductive; II: non-reproductive), while the second letter refers to the reproductive status of females (N: non-reproductive; G: reproductive). Bars with different letters above them are significantly different from each other using a. Chi-square analysis for proportions followed by a multiple comparisons test for proportions $(p<0.05)$. 


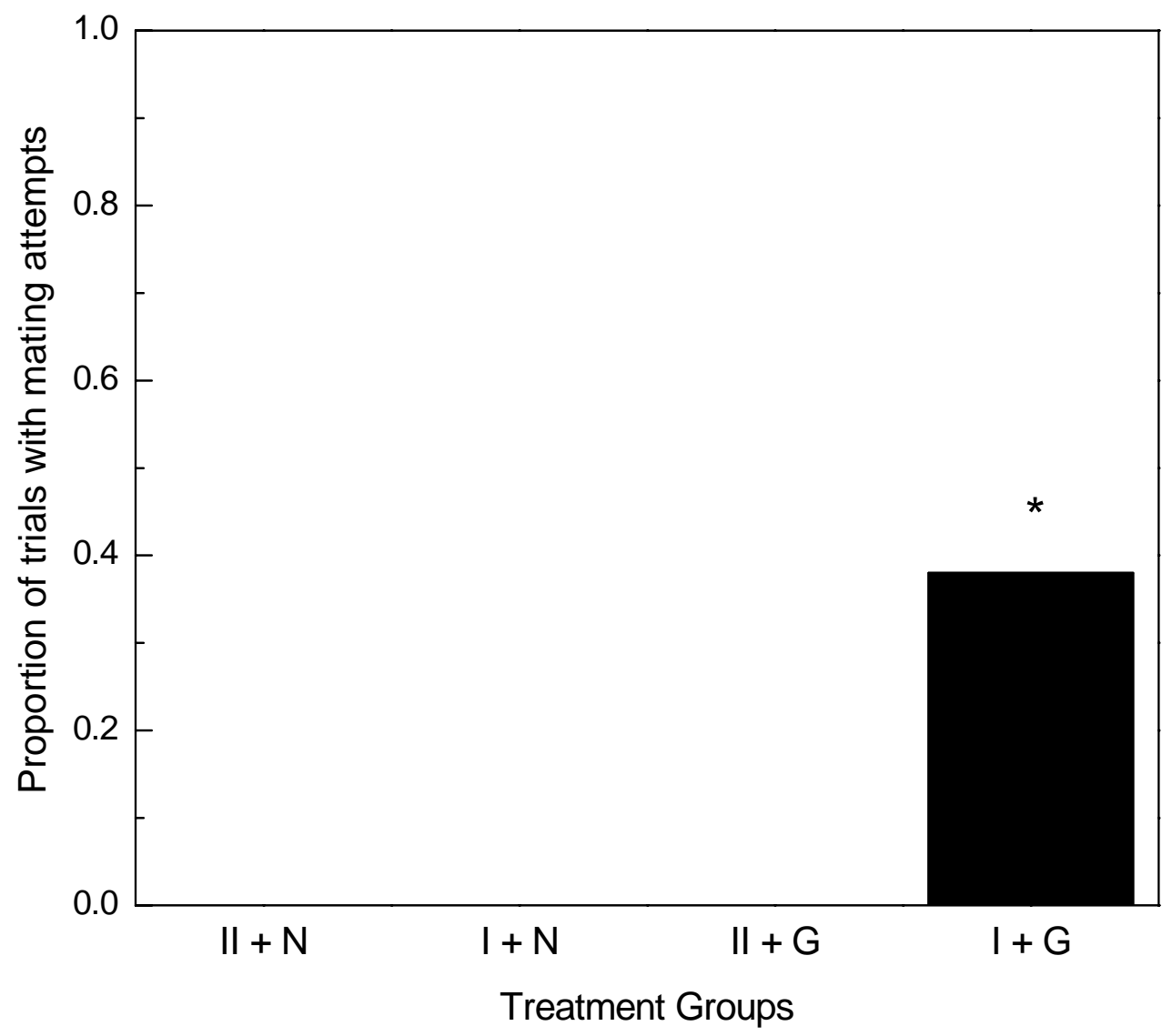

Figure 4. Proportion of experimental trials that resulted in mating attempts. Titles along the $x-$ axis represent the reproductive state of the male (first letters) and the female (second letters). Initial letter in the treatment groups refers to the reproductive status of males (I: reproductive; II: non-reproductive), while the second letter refers to the reproductive status of females (N: nonreproductive; G: reproductive). Asterisks refers to a statistical difference using chi-square analysis $\left(\chi^{2}=24, d f=3, \mathrm{p}<0.001\right)$. 
(a)

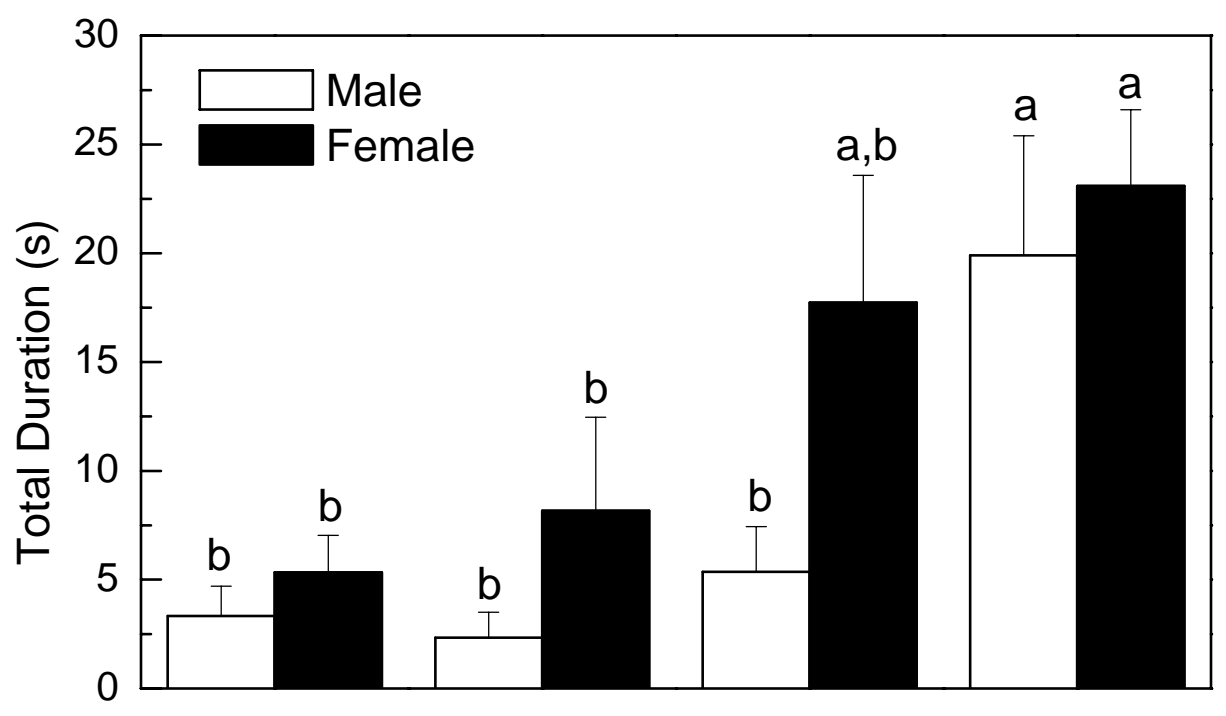

(b)

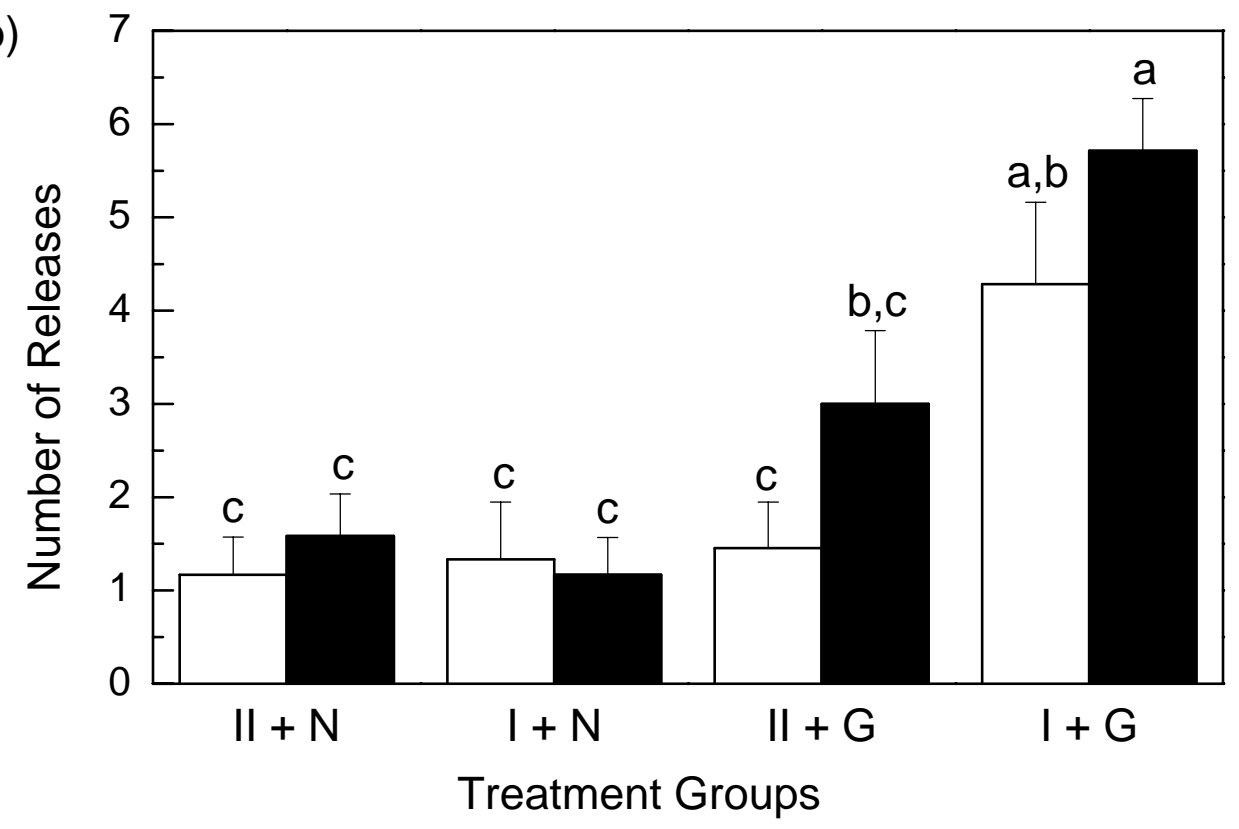

Figure 5. Mean ( \pm SEM) total duration of urine release $(A)$ and number of urine releases (B) over 20 minute interactions for crayfish in different reproductive states. Males are indicated by the open bar and females are the hatched bars. Titles along the $\mathrm{x}$-axis represent the reproductive state of the male (first letters) and the female (second letters). Initial letter in the treatment groups refers to the reproductive status of males (I: reproductive; II: non-reproductive), while the second letter refers to the reproductive status of females (N: non-reproductive; G: reproductive). Bars with different letters represent statistically significant differences using a two-way factorial MANOVA with Fisher-LSD post-hoc test; $\mathrm{p}<0.05$ ). $N=11$ for II $+\mathrm{N}, 6$ for $\mathrm{I}+\mathrm{N}, 12$ for II $+\mathrm{G}$, and 21 for $\mathrm{I}+\mathrm{G}$. 

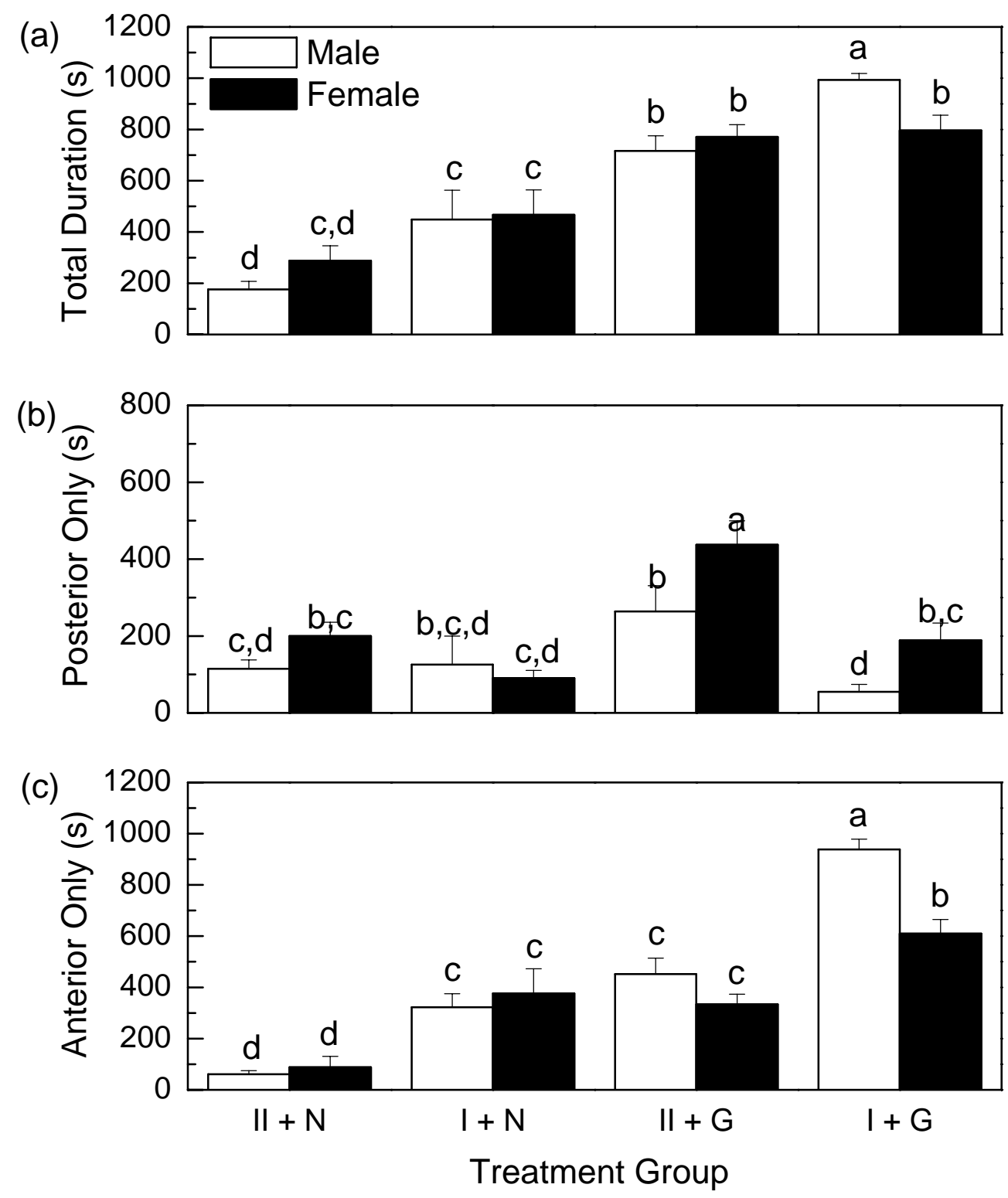

Figure 6. Mean $( \pm$ SEM) duration of both currents $(A)$, posterior only (B), and anterior only (C) in seconds over 20 minute interactions for crayfish in different reproductive states. Males are indicated by the open bar and females are the hatched bars. Titles along the $\mathrm{x}$-axis represent the reproductive state of the male (first letters) and the female (second letters). Initial letter in the treatment groups refers to the reproductive status of males (I: reproductive; II: non-reproductive), while the second letter refers to the reproductive status of females (N: non-reproductive; G: reproductive). Bars with different letters represent statistically significant differences using a two-way factorial MANOVA with Fisher-LSD post-hoc test; $\mathrm{p}<0.05$. $N=11$ for II+N, 6 for $\mathrm{I}+\mathrm{N}, 12$ for $\mathrm{II}+\mathrm{G}$, and 21 for $\mathrm{I}+\mathrm{G}$. 
(a)

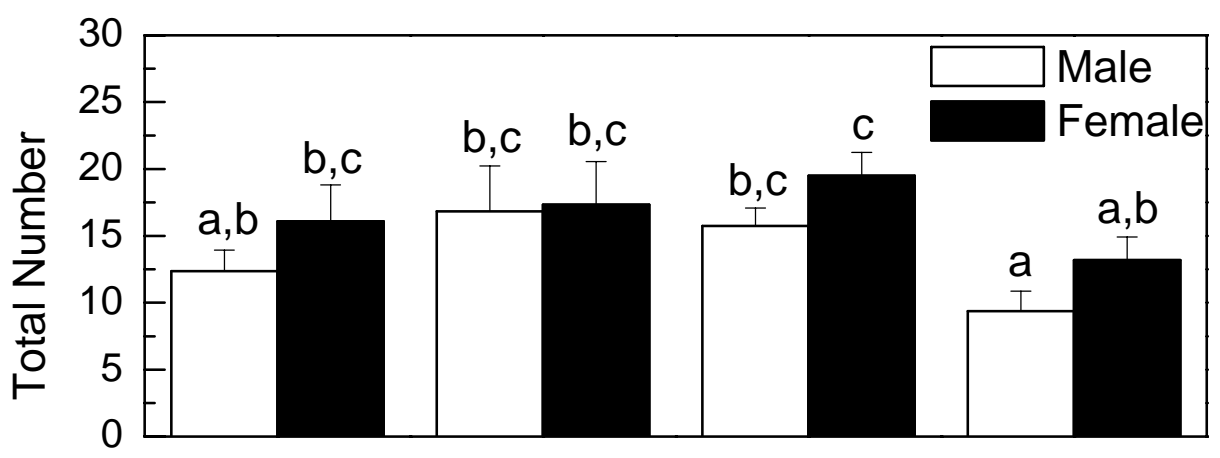

(b)

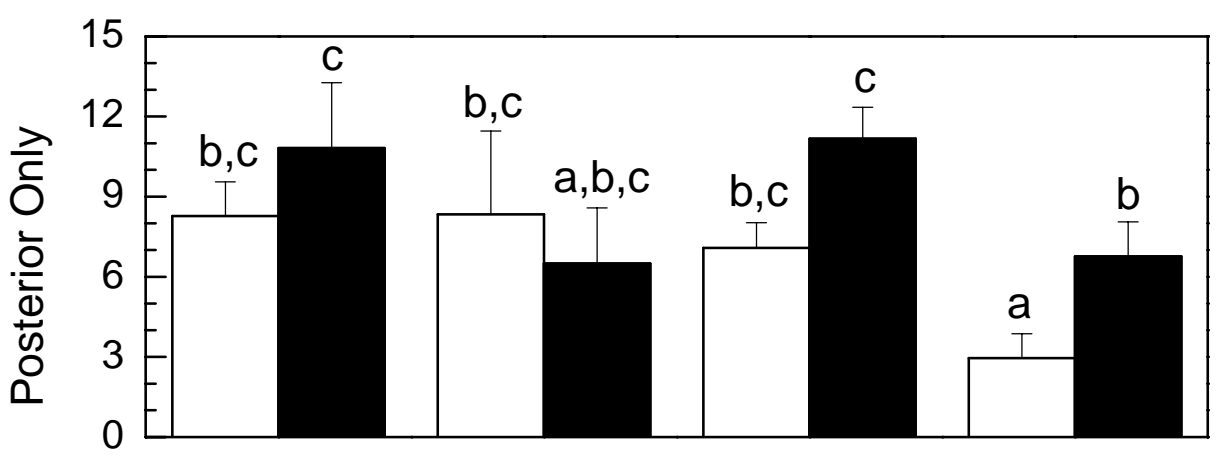

(c)

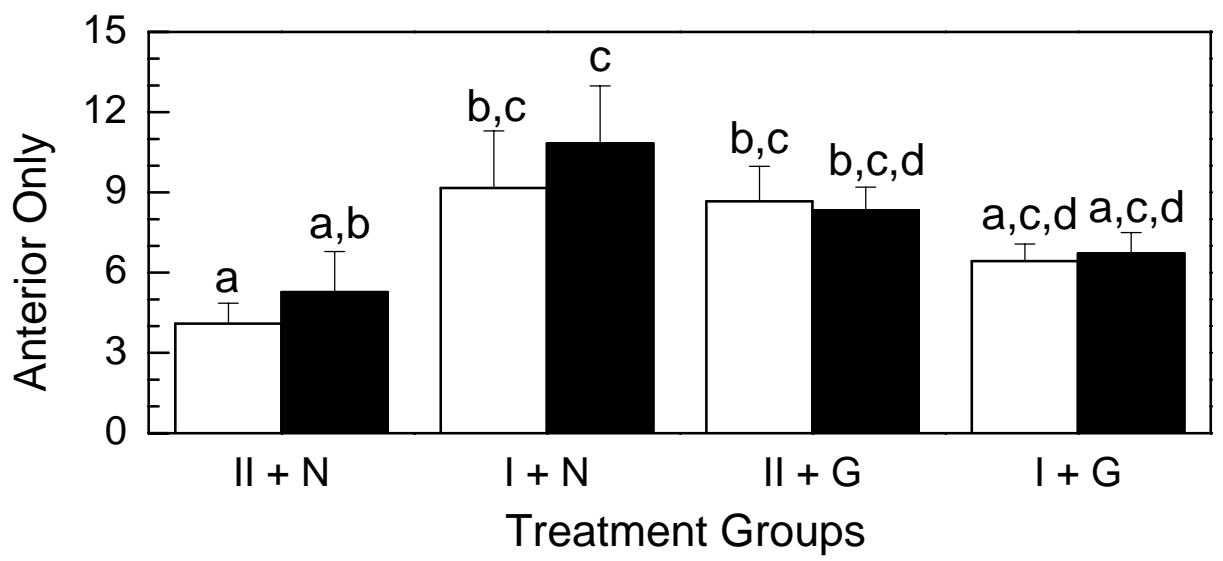

Figure 7. Mean ( \pm SEM) for number total number of combined currents (A), posterior currents (B) and anterior currents (C) over 20 minute interactions for crayfish in different reproductive states. Titles along the $\mathrm{x}$-axis represent the reproductive state of the male (first letters) and the female (second letters). Initial letter in the treatment groups refers to the reproductive status of males (I: reproductive; II: non-reproductive), while the second letter refers to the reproductive status of females (N: non-reproductive; G: reproductive). Males are indicated by the open bar and females are the hatched bars. Bars with different letters represent statistically significant differences using a two-way factorial MANOVA with Fisher-LSD post-hoc test; $\mathrm{p}<0.05 . N=$ 11 for $\mathrm{II}+\mathrm{N}, 6$ for $\mathrm{I}+\mathrm{N}, 12$ for $\mathrm{II}+\mathrm{G}$, and 21 for $\mathrm{I}+\mathrm{G}$. 

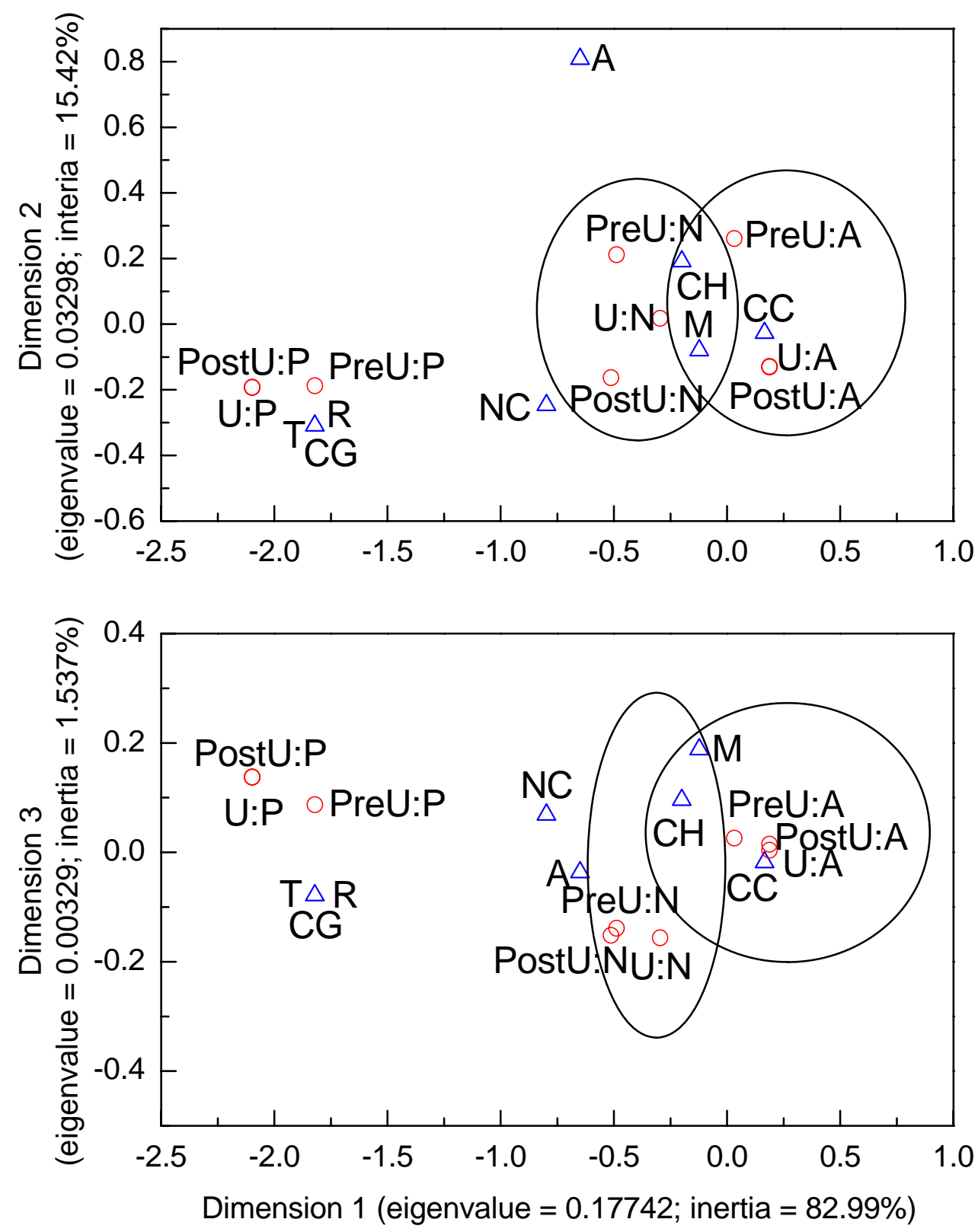

Figure 8. Two-dimensional plot of row and column coordinates illustrating the male crayfish correspondence analysis of social behaviors, urine release and current generation from $\mathrm{I}+\mathrm{G}$ treatment group. Triangles represent behavior; circles represent a urine release and current generation (See Table 1 for abbreviations). Circles are added to draw attention to the closest correlations in space and time. 

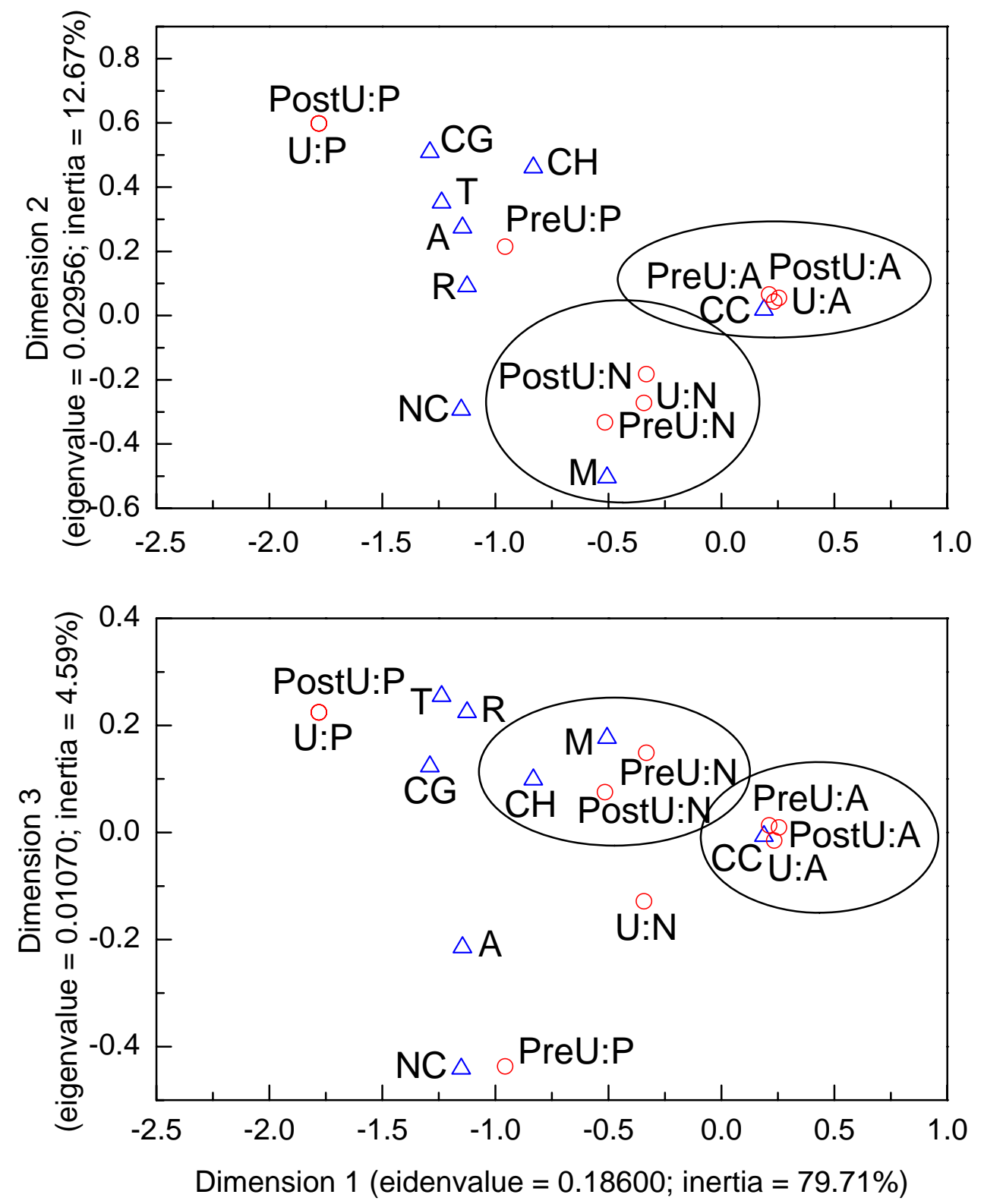

Figure 9. Two-dimensional plot of row and column coordinates illustrating the female crayfish correspondence analysis of social behaviors, urine release and current generation from $\mathrm{I}+\mathrm{G}$ treatment group. Triangles represent behavior; circles represent a urine release and current generation (See Table 1 for abbreviations). Circles are added to draw attention to the closest correlations in space and time. 
TABLE 1. An ethogram for crayfish current generation, urine release, and social behavior, used for video analysis and in Figs. 8 and 9.

\begin{tabular}{|c|c|}
\hline ABBREVIATION & DEFINITION \\
\hline \multicolumn{2}{|l|}{ Currents } \\
\hline A & Anterior current generation \\
\hline $\mathrm{P}$ & Posterior current generation \\
\hline $\mathrm{N}$ & No currents \\
\hline \multicolumn{2}{|l|}{ Urine release } \\
\hline PreU & 5 seconds prior to urine release \\
\hline $\mathrm{U}$ & During urine release \\
\hline PostU & 5 seconds after release stops \\
\hline \multicolumn{2}{|l|}{ Behavior } \\
\hline $\mathrm{NC}$ & No contact \\
\hline A & Approach \\
\hline $\mathrm{CC}$ & Physical chelae contact \\
\hline $\mathrm{CH}$ & Chelae hold \\
\hline $\mathrm{CG}$ & Chelae grab \\
\hline $\mathrm{R}$ & Retreat away from opponent \\
\hline $\mathrm{T}$ & Tailflip away from opponent \\
\hline M & Mating behavior \\
\hline
\end{tabular}

